\title{
CENÁRIOS PROSPECTIVOS E A DINÂMICA DE SISTEMAS: PROPOSTA DE UM MODELO PARA 0 SETOR CALÇADISTA
}

PROSPECTIVE SCENARIOS AND SYSTEM DYNAMICS: A MODEL FOR THE FOOTWEAR SECTOR

\section{RESUMO}

Esta pesquisa visa propor uma forma de análise sistêmica do setor calçadista que integre a abordagem de Cenário Prospectivos à Dinâmica de Sistemas. Objetiva-se com isso disponibilizar alternativas que possibilitem análise, descrição e simulação de tendências de mercado para um período de cinco anos. Para a construção dos cenários, adotou-se o método descrito por Grumbach. Após a geração dos cenários, realizou-se a integração com a modelagem hard da Dinâmica de Sistemas. Os resultados indicam que a abordagem proposta pode contribuir para apontar oportunidades e ameaças do ambiente externo, bem como pontos fortes e fracos do ambiente interno, a fim de auxiliar nas decisões estratégicas e na adoção de procedimentos adequados para proteger o mercado calçadista pesquisado.

\section{Henrique Dias Blois}

Professor da Faculdade de Ciências Econômicas, Administrativas e Contábeis, Universidade de Passo Fundo

blois@upf.br

\section{João Carlos Souza}

Professor do Departamento de Arquitetura e Urbanismo, Universidade Federal de Santa Catarina jcsouza@arq.ufsc.br

Recebido em 02.06.2006. Aprovado em 19.07.2007

Avaliado pelo sistema double blind review

Editor Científico: Rafael Goldszmidt

ABSTRACT This research proposes a way of systemically analyzing the footwear sector that integrates the Prospective Scenarios approach and System Dynamics. In doing so the objective is to suggest alternatives that make it possible to analyze, describe and simulate market trends for a period of up to five years. The method described by Grumbach was used for constructing the scenarios, which were subsequently integrated with the 'hard' modeling approach of System Dynamics. The results indicate that the proposed approach may contribute when it comes to indicating the opportunities and threats from the external environment and the strengths and weaknesses in the internal environment. The approach also helps when taking strategic decisions and adopting suitable procedures to protect the footwear market in which the research was carried out.

PALAVRAS-CHAVE Agência de desenvolvimento regional, Vale dos Sinos, cenários prospectivos, dinâmica de sistemas, setor calçadista.

KEYWORDS Regional development agency, Vale dos Sinos, prospective scenarios, system dynamics, footwear sector 


\section{INTRODUÇÃO}

Nas últimas décadas, o vale dos Sinos, localizado na Região Metropolitana de Porto Alegre, capital do Rio Grande do Sul, vem apresentando diminuição no número de empresas atuantes nessa localidade, decorrente de problemas relacionados ao deslocamento de empresas calçadistas para o Nordeste do Brasil, bem como pela concorrência externa, principalmente pela produção chinesa de calçados. No período de 1991 a 2001, houve uma queda de aproximadamente $9,0 \%$ no total de empresas voltadas para o setor calçadista. Isso pode ser visualizado na tabela a seguir.

Em virtude disso, estudos que possibilitem diagnosticar e prognosticar as tendências do mercado mundial de calçados ajudarão a constatar os desafios técnicos e metodológicos que essa região enfrentará para continuar sendo um importante cluster calçadista. Como cluster entendemos um "agrupamento geograficamente concentrado de empresas inter-relacionadas e instituições correlatas, numa determinada área, vinculadas por elementos comuns e complementares" (PORTER, 1999, p. 102).

Os Cenários Prospectivos apresentam-se como uma ferramenta que possibilitaria a empresas dessa região avaliar alternativas futuras de conduta. Para Marcial e Grumbach (2005), os cenários propiciam um ambiente que enriquece o debate sobre questões críticas relacionadas ao futuro da organização e permitem que dirigentes de empresas tomem decisões de risco com mais clareza. Permitem, ainda, a identificação de oportunidades e de ameaças ao negócio, promovendo o desenvolvimento e a análise de novas opções perante as mudanças no ambiente externo.
A Dinâmica de Sistemas (DS) é uma metodologia que busca mapear estruturas de sistemas organizacionais ou sociais (MARTELANC, 1998) e procura examinar a interrelação de suas forças em contexto amplo, entendendo-as como parte de um processo comum. Por meio da simulação, a DS pretende compreender como o sistema em foco evolui no tempo e como as mudanças em suas partes afetam todo o seu comportamento.

É nesse contexto que a integração entre Cenários Prospectivos e Dinâmica de Sistemas possibilita diagnosticar e prognosticar um determinado sistema, pois a união dessas ferramentas possibilita simular os cenários no tempo.

Diante do exposto, cabe questionar se a criação de um modelo que integre cenários prospectivos à dinâmica de sistemas para o cluster calçadista permite melhor análise futura dessa região. Assim, o presente estudo tem como objetivo propor a aplicação conjunta dessas duas ferramentas para a análise de um cluster calçadista.

Para a coleta de dados, contataram-se empresários, dirigentes sindicais e professores do setor calçadista. Sete deles disponibilizaram-se para participar de todas as etapas da pesquisa de campo, garantindo o número mínimo necessário à utilização do método Grumbach.

\section{CLUSTERS DO SETOR CALÇADISTA: PANORAMA DA INDÚSTRIA}

Conforme Anderson (2001), a indústria mundial de calçados apresenta um processo evolutivo no qual se destaca a localização da produção em países ou regiões que ofe-

Tabela 1 - Perfil do Vale dos Sinos entre os anos de 1991 a 2001

\begin{tabular}{|l|c|c|}
\hline \multirow{2}{*}{ ATIVIDADE } & NÚMERO DE EMPRESAS & NÚMERO DE EMPRESAS \\
\hline Fabricantes de componentes & 1991 & 2001 \\
\hline Curtumes & 223 & 191 \\
\hline Fabricantes de máquinas e equipamentos & 135 & 92 \\
\hline Agentes de exportação & 45 & 38 \\
\hline Empresas prestadoras de serviço & 70 & 47 \\
\hline Fabricantes de artigos de couro & 710 & 759 \\
\hline Fabricantes de borracha & 52 & 41 \\
\hline Outros & 26 & 26 \\
\hline Total & 80 & 88 \\
\hline
\end{tabular}

Fonte: ASSINTECAL 2005. 
reçam salários baixos e mão-de-obra abundante, devido à natureza de mão-de-obra intensiva e às limitadas possibilidades de automação da produção. Observa-se, também, que a redução dos custos constitui-se no principal elemento da competitividade das empresas.

A autora argumenta que a oferta do setor não é homogênea, pois reúne um conjunto variado de produtos que se diferenciam tanto pelo mercado consumidor (calçados masculinos, femininos, infantis e esportivos) quanto pelos insumos utilizados (couro, plástico ou combinados). Além disso, os produtos diferenciam-se por qualidade, marca, design e moda, ocorrendo uma segmentação importante de mercado.

Para Costa (1993), a competição não ocorre somente por meio dos preços, já que o calçado é um produto de moda, com ciclo de vida curto, contendo vários modelos e estilos, fabricados com diferentes materiais para atender diferentes necessidades. Em razão disso, na indústria calçadista, não existem economias de escala significativas. A qualidade final dos produtos tem relação direta com a qualificação de mão-de-obra pela sua natureza intensiva. A tecnologia de produção varia de acordo com as estratégias genéricas de produção. Quanto maior a diferenciação, maior a necessidade de tecnologia mais sofisticada. Inversamente, a tecnologia menos sofisticada atende a estratégia de custo, com produtos padronizados a preços baixos.

Nas últimas décadas, observou-se o deslocamento da produção de calçados em direção às regiões menos desenvolvidas em duas fases. Na primeira, que ocorreu a partir da década de 1970, verificou-se a transferência da produção para os chamados Tigres Asiáticos (Coréia do Sul, Taiwan e Hong Kong) e para o Brasil. Esses países, que tinham uma pequena participação no comércio externo mundial, chegaram ao final dos anos 80 com cerca de um terço das exportações mundiais. No entanto, à medida que foram avançando em seu processo de industrialização, houve um aumento do salário principalmente nos países asiáticos. Isso ocasionou um segundo deslocamento, nos anos 1980, em direção à China, Filipinas, Indonésia, Tailândia e outros países com disponibilidade de mão-deobra a baixo custo (FENSTERSEIFER, 1995).

No caso brasileiro, até o final da década de 1960, a indústria de calçados brasileira era exclusivamente direcionada para o mercado interno, e seu dinamismo dependia do crescimento da população e de sua renda per capita (HENKIN, 2004). No final dessa década, a indústria de calçados brasileira entrou no mercado internacional, exportando, principalmente, calçados de couro femininos.

$\mathrm{O}$ aumento de escala requerido pelo volume dos pe- didos dos importadores levou, na década de 1970, a um processo de modernização e maior mecanização da produção. Houve ganho de aprendizado na produção para um mercado mais exigente e melhora na qualidade do calçado. Nos anos 1970 e 1980, a produção para o mercado externo foi multiplicada por cinco e, ao longo dessas duas décadas, as vendas foram concentradas no mercado norte-americano, absorvendo mais de dois terços das exportações brasileiras de calçados.

Por outro lado, Henkin (2005) salienta que o desempenho negativo recente do setor de calçados brasileiro teve como principais condicionantes a defasagem cambial e a restrição monetária, provocadas pelo Plano Real, pela desvalorização das moedas do Sudeste Asiático e pelo aumento das vendas de calçados chineses ao mercado norte-americano.

Para a Abicalçados (2005), atualmente a produção gaúcha de calçados responde por 30\% da produção nacional, $70 \%$ das exportações do setor e 135 mil empregos diretos. Localizado próximo à capital do estado do Rio Grande do Sul, ele abrange 26 municípios, sendo os principais: Novo Hamburgo, Campo Bom, Taquara, São Leopoldo, Parobé, Igrejinha e Sapiranga. O setor coureiro-calçadista do vale dos Sinos está baseado em empresas fabricantes de calçados de couro feminino e tem ao seu redor várias empresas que compõem a cadeia produtiva do setor: curtumes, beneficiadoras de couro e peles; fabricantes de componentes para calçados (metálicos, borracha, sintéticos etc.); fornecedoras de máquinas e equipamentos e prestadoras de serviços de transporte e exportação.

Em torno desse cluster, formou-se uma estrutura organizacional com seis associações industriais, duas associações profissionais, uma empresa organizadora de eventos, quatro centros tecnológicos para a prestação de serviços especializados e treinamento de mão-de-obra, além de escolas técnicas e universidades (ABICALÇADOS, 2005).

\section{MÉTODOS PARA ANÁLISE DO SETOR CALÇADISTA: CENÁRIOS PROSPECTIVOS E DINÂMICA DE SISTEMAS}

Nesta etapa do trabalho, apresentamos os instrumentos utilizados na pesquisa para análise do setor calçadista do vale dos Sinos. Primeiramente, discorremos sobre os Cenários Prospectivos, apontando as suas origens e aplicabilidade. Em seguida, abordamos a Dinâmica de Sistemas, focando a modelagem hard, porquanto se mostrou mais útil para o entendimento de nosso objeto. 


\section{Os Cenários Prospectivos}

Marcial e Grumbach (2005) salientam que as técnicas prospectivas - entre elas os Cenários - começaram a ser utilizadas de forma sistemática entre os militares durante a Segunda Guerra Mundial, principalmente nos Estados Unidos, como um mecanismo de apoio à formulação de estratégias bélicas.

A metodologia de Cenários, segundo Godet (2000), foi aplicada na França pela primeira vez por ocasião de estudo de prospecção geográfica realizado por conta da DATAR (Délégation à l'Aménagement du Territoire et à l'Action Régionale), em 1970. A partir daí, esse método foi adotado em setores como indústria, agricultura, demografia e emprego, e aplicado a diferentes níveis geográficos.

Moretti (2002) salienta que, no Brasil, a prática de elaboração de cenários é recente. As primeiras empresas a utilizarem tal prática foram a Eletrobrás, em 1987, e a Petrobras, em 1989, no final da década de 1980, em razão de operarem com projetos de longo período de maturação, o que exigia visão de longo prazo. Também no final dessa década, o trabalho elaborado pelo BNDES em 1989, de conteúdo mais econômico, teve grande impacto e abriu grande discussão política sobre os cenários do Brasil. No final da década de 1980 e início da década de 1990, surgiram novos estudos prospectivos no país.

De acordo com Bethlem (2002), os métodos de elaboração de cenários que possuem base conceitual, passos definidos e filosofia são os seguintes: método descrito por Michel Godet; método descrito pela General Electric (GE); método descrito por Peter Schwartz ou da Global Business Network (GBN); método descrito por Michael Porter; e o método descrito por Grumbach (metodologia escolhida nessa pesquisa, pois incorpora as vantagens de dois métodos de elaboração de cenários - o de Godet e o de Porter).

O método de elaboração de cenários exploratórios descritos por Godet (2000) compõe-se basicamente de seis etapas: 1 - Delimitação do sistema e do ambiente; 2 Análise estrutural do sistema e do ambiente; 3 - Seleção dos condicionantes do futuro; 4 - Geração de cenários alternativos; 5 - Testes de consistência, ajustes e disseminação; 6 - Opções estratégicas e planos de monitoração estratégica. No método descrito por Porter (1999), as etapas são as seguintes: 1- Propósito de estudo e histórico, e da situação atual; 2 - Identificação das incertezas críticas e classificação; 3 - Comportamento futuro das variáveis; 4- Análise de cenários e consistência; 5 - Análise da concorrência; 6 - Elaboração das histórias de cenários; e 7 - Elaboração das estratégias competitivas.

\section{A Dinâmica de Sistemas}

Para Fernandes (2001), a Dinâmica de Sistemas busca entender a evolução de um sistema ao longo do tempo. A premissa central da abordagem é que o comportamento de um sistema é determinado por sua estrutura interna. Assim, usando de uma linguagem própria para a modelagem, é possível investigar o seu comportamento ao longo do tempo.

Bastos (2003) afirma que, na modelagem, a DS assume que a análise de uma situação pode ser empreendida de um ponto de vista objetivo externo e que a estrutura e os processos dinâmicos do mundo real podem ser recriados em diagramas com simbologia específica e modelos matemáticos.

Para Andrade (1997), a DS procura compreender a estrutura e o comportamento dos sistemas compostos por enlaces de feedback interagentes. Para essa compreensão, utilizam-se dois tipos de notação: Diagramas de Enlace Causal (modelagem soft) e Diagramas de Estoque e Fluxo (modelagem hard).

Maani e Cavana (2000) salientam a distinção entre modelagem soft e hard. A modelagem soft refere-se a abordagens conceituais que buscam maior realismo, pluralismo e uma intervenção mais holística que a modelagem hard. Os conceitos soft e hard são também relacionados às idéias de qualitativo e quantitativo, respectivamente.

\section{A modelagem hard da Dinâmica de Sistemas}

Ainda que de grande importância, os Diagramas Causais não são aptos para a simulação das estruturas sistêmicas ao longo do tempo. Nesse caso, Franco (2005) argumenta que podem ser utilizados os Diagramas de Estoque e Fluxo, que são adequados à simulação - abordagem quantitativa da DS.

Segundo Andrade (1997), em um Diagrama de Estoque e Fluxo, a estrutura do sistema é representada matematicamente, permitindo quantificar as relações de causa e efeito entre os elementos do sistema. Na perspectiva da DS, qualquer sistema pode ser descrito em um Diagrama de Estoque e Fluxo, numa linguagem composta de quatro elementos:

a) estoques (stocks ou níveis): representam as acumulações de um recurso;

b) fluxos (flows): são atividades que produzem crescimento ou redução dos estoques, o movimento de materiais e a informação dentro do sistema;

c) auxiliares (conversores e constantes): são componentes para a realização de operações algébricas, que processam informações a respeito dos estoques e fluxos ou 
representam fontes de informação externas ao sistema;

d) conectores: são links de informação que descrevem a relação entre estoques, fluxos e auxiliares.

Para Bastos (2003), todo o comportamento dinâmico de um sistema está baseado no princípio da acumulação, uma vez que os fluxos acumulam-se em estoques. Ou seja, para o autor, "o comportamento dinâmico surge quando algo flui por algum meio, acumulando-se (ou esgotando-se) de alguma forma. Na modelagem com Diagramas de Estoque e Fluxo, variáveis, físicas ou não, podem fluir pelos fluxos, acumulando-se nos estoques" (BASTOS, 2003).

\section{PROPOSTA DE UM MODELO DE INTEGRAÇÃO ENTRE CENÁRIOS PROSPECTIVOS E A DINÂMICA DE SISTEMAS}

Nesta etapa, apresenta-se o modelo proposto neste trabalho, que pretende integrar Cenários Prospectivos, por meio do método Grumbach, com a modelagem hard da Dinâmica de Sistemas para um cluster calçadista.

\section{Apresentação do modelo}

Por meio de levantamento bibliográfico e entrevistas com sete peritos, foi estruturado o diagnóstico do objeto de estudo. Bethlem (2002) considera o método Delphi uma das melhores técnicas qualitativas de previsão. Consiste em criar um questionário e obter respostas dos especialistas, que vão sendo utilizadas na obtenção de consensos e na formulação de novas perguntas e assim por diante. É uma técnica circular e interativa. O produto final de sua aplicação é uma média ponderada das opiniões dos especialistas sobre a probabilidade de ocorrência dos eventos analisados. Com esse diagnóstico, foi possível selecionar os 22 eventos futuros preliminares, passíveis de acontecer no período preestabelecido, no caso deste modelo, um período de cinco anos (período estimado até 31.12.2010).

Com a ajuda dos mesmos peritos, os eventos preliminares foram submetidos a duas rodadas de discussão, por meio do método Delphi. Na metodologia Grumbach, os eventos preliminares devem ser enviados aos peritos para que estipulem a "probabilidade de ocorrência", estabeleçam a "pertinência dos eventos" e realizem uma "autoavaliação", resultando, assim, dez eventos definitivos e gerando 1.024 cenários futuros passíveis de ocorrer. $\mathrm{Na}$ probabilidade de ocorrência dos eventos, os peritos utilizaram, como referencial, percentuais que variavam de $0 \%$ a $100 \%$, para um período futuro de cinco anos. Na perti- nência, cada perito atribuiu notas de 1 a 9 , de acordo com o grau de pertinência do evento com relação ao cluster do vale dos Sinos. Por fim, na auto-avaliação, cada perito avaliou o seu grau de conhecimento sobre cada evento considerado isoladamente, atribuindo valores de 1 a 9 .

Com o auxílio do método Delphi, os peritos participaram da segunda consulta. Esse número de rodadas foi suficiente para identificar os dez "eventos definitivos" selecionados (foram selecionados apenas os eventos que apresentaram pertinência superior a 7 evento muito pertinente), as respectivas "probabilidades" (selecionaram-se os eventos com probabilidades superiores a $60 \%$ - eventos muito prováveis de ocorrer até 31.12.2010) e os "desvios padrão" (o método Grumbach considera que um desvio padrão igual ou menor que 20 indica razoável grau de confiança na probabilidade média calculada para um determinado evento), critérios que foram utilizados para a escolha dos eventos definitivos. O Quadro 1 mostra tanto os eventos futuros preliminares (22 ao todo) quanto os dez eventos definitivos, destacados no quadro.

Tendo-se os eventos definitivos, foi enviada aos mesmos peritos a matriz de impactos cruzados, que gerou a matriz de impactos medianos (média das notas dos sete peritos). Posteriormente, geraram-se, por meio do software PUMA (Pointwise Unconstrained Minimization Approach - software idealizado por Raul Grumbach para a geração de Cenários Prospectivos), os Cenários Prospectivos, onde o método Grumbach se utiliza do teorema de Bayes (teorema das probabilidades condicionantes) tanto para a geração dos cenários quanto para as probabilidades de sua ocorrência. Na integração entre Cenários Prospectivos e a Dinâmica de Sistemas, utilizaram-se também os dez primeiros cenários, porque são os de maior probabilidade de ocorrência.

Os peritos foram consultados para indicar o impacto que os dez eventos definitivos causariam sobre a produção de calçados fabricados no cluster do Vale dos Sinos. Após a integração dos Cenários Prospectivos à Dinâmica de Sistemas, realizaram-se as simulações e a interpretação dos cenários. De posse desses elementos, foi possível estabelecer um prognóstico para o objeto ora em estudo.

No final do modelo e tendo um prognóstico, foi possível estabelecer medidas que podem ser tomadas para aproveitar as oportunidades e os pontos fortes, bem como se proteger contra as ameaças e os pontos fracos. Por fim, visto que o modelo é sistêmico, o processo novamente se iniciou com um novo diagnóstico, com o qual as etapas anteriormente descritas seriam reiniciadas. $\mathrm{O}$ processo descrito pode ser mais bem visualizado na Figura 1. 


\section{APLICAÇÃO DA METODOLOGIA E RESULTADOS OBTIDOS}

Nesta seção, apresentaremos a configuração dos cenários passíveis de acontecer e as possíveis conseqüências para o setor calçadista analisado. Lembramos que esses cenários foram construídos a partir dos eventos definitivos levantados pelos peritos.

\section{Pesquisa de campo: diagnóstico e escolha dos eventos}

Identificados os eventos definitivos (aqueles de maior pertinência e probabilidade, e menor desvio padrão), o software PUMA calculou os cenários possíveis pela combinação das ocorrências ou não de eventos, conforme $o$ teorema de Bayes.
De acordo com os dados colhidos na geração de Cenários Prospectivos, justifica-se a seleção de dez cenários para análise, visto que eles representam $63,70 \%$ da probabilidade total de ocorrência dos cenários; os demais 1014 cenários representam 36,30\% de probabilidade de ocorrência. Na Tabela 3, observa-se a ocorrência ou não dos eventos nos dez primeiros cenários.

\section{A interpretação dos cenários}

A interpretação de cenários pode ser feita de várias maneiras na metodologia proposta por Marcial e Grumbach (2005). Todavia, os autores sugerem que sejam interpretados os cenários mais prováveis (de maior probabilidade), o cenário de tendência (aquele que corresponde à projeção dos acontecimentos passados sobre o caminho futuro a ser percorrido pela organização, indicando a

Quadro 1 - Mapa de opinião por perito ( ${ }^{a}$ consulta)

Estudo: 0 setor calçadista do Vale dos Sinos - 2010

\section{EVENTOS}

\section{Valorização do dólar}

2. Utilização de marca própria

3. Utilização de design próprio

4. Concorrência com calçados de maior valor agregado

5. Utilização de tecnologias avançadas na produção

6. Expansão do mercado do vale dos Sinos para outros continentes

7. Aumento do custo da matéria-prima

8. Crescimento de tarifas sobre a importação de calçados

9. Redução de impostos

10. Instalação de consórcios de PMEs

11. Migração de fabricantes para outras regiões

12. Condições das modalidades de transporte

13. Comercialização realizada pelos próprios produtores

14. Aumento do custo da mão-de-obra

15. Aumento da taxa de juros

16. Aumento no consumo de calçados no mercado externo

17. Aumento no consumo de calçados no mercado interno

18. Disponibilidade de operadores logísticos

19. Disponibilidade de prestadores de serviços logísticos

20. Condições de competitividade do cluster do vale dos Sinos

21. Instalação de uma Agência de Desenvolvimento Regional

22. Intercâmbio entre o vale dos Sinos e outros pólos calçadistas 
possibilidade de ocorrência de rupturas e o surgimento de fatos novos que interessem à organização) e o cenário ideal (aquele que contempla todas as ocorrências posi- tivas e desconsidera as ocorrências negativas, do ponto de vista do decisor estratégico, contendo apenas eventos favoráveis à organização).

Figura 1 - Modelo sistêmico de integração entre Cenários Prospectivos e Dinâmica de Sistemas

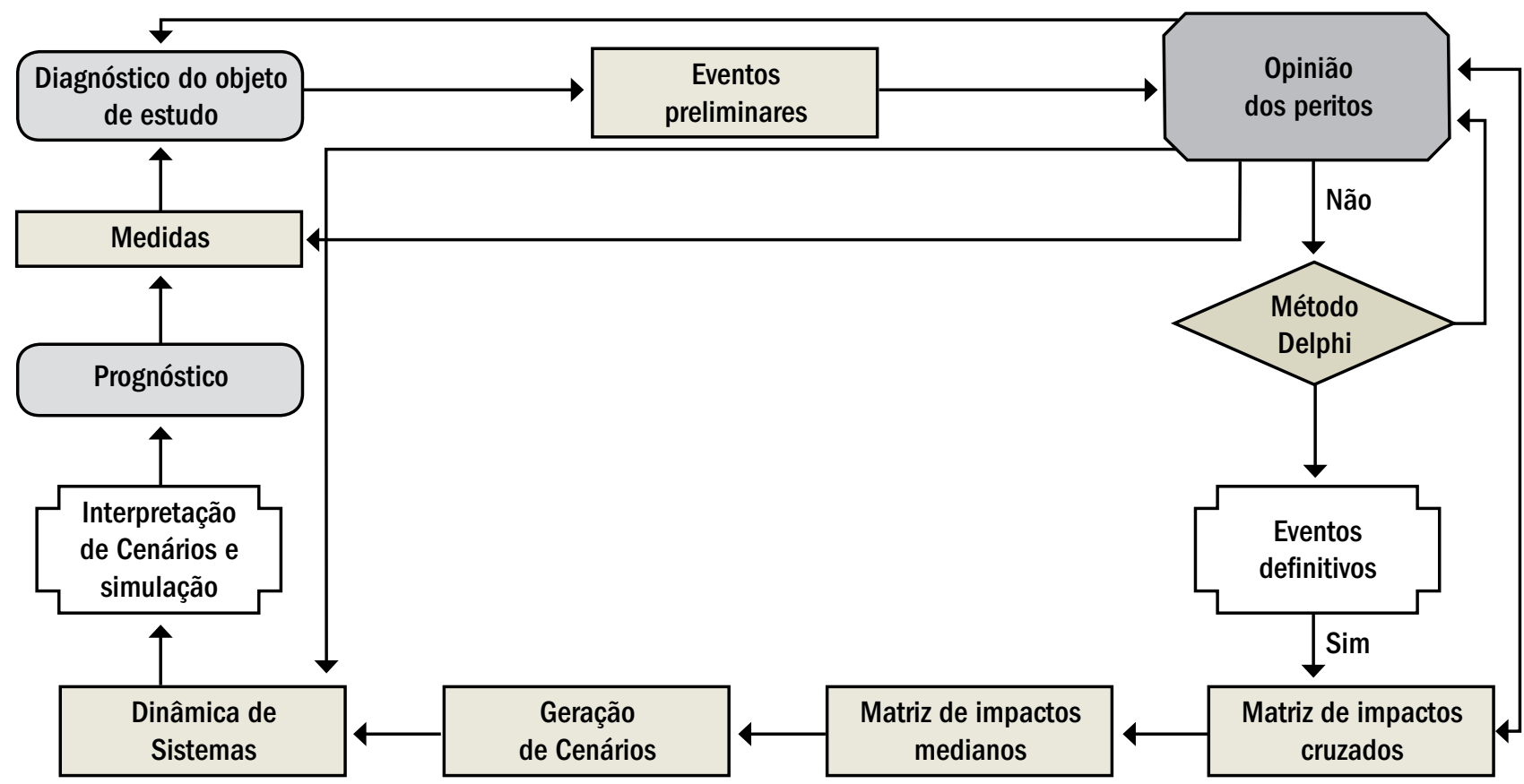

Legenda:

Início e fim

Operação

Conferência

Executante

Decisão

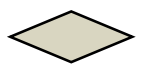

Tabela 3 - Geração de Cenários Prospectivos

\begin{tabular}{|l|c|c|c|c|c|c|c|c|c|c|c|c|}
\hline CENÁRIOS & PROB. (\%) & 1.VAL. & 2.UTIL. & 4.CONC. & 6.EXP. & 12.COND. & 17.AUM. & 18.DISP. & 19.DISP. & 20.COND. & 21.INST. \\
\hline Cenário 1 & 30,1346667 & Ocorre & Ocorre & Ocorre & Ocorre & Ocorre & Ocorre & Ocorre & Ocorre & Ocorre & Ocorre \\
\hline Cenário 2 & 5,6673333 & Ocorre & Ocorre & Ocorre & Ocorre & Ocorre & Não & Ocorre & Ocorre & Ocorre & Ocorre \\
\hline Cenário 3 & 5,2073333 & Ocorre & Ocorre & Ocorre & Ocorre & Ocorre & Ocorre & Não & Ocorre & Ocorre & Ocorre \\
\hline Cenário 4 & 4,7853333 & Ocorre & Não & Ocorre & Ocorre & Ocorre & Ocorre & Ocorre & Ocorre & Ocorre & Ocorre \\
\hline Cenário 5 & 4,4586667 & Não & Ocorre & Ocorre & Ocorre & Ocorre & Ocorre & Ocorre & Ocorre & Ocorre & Ocorre \\
\hline Cenário 6 & 4,4106667 & Ocorre & Ocorre & Ocorre & Ocorre & Não & Ocorre & Ocorre & Ocorre & Ocorre & Ocorre \\
\hline Cenário 7 & 2,9866667 & Ocorre & Ocorre & Ocorre & Ocorre & Ocorre & Ocorre & Ocorre & Ocorre & Ocorre & Não \\
\hline Cenário 8 & 2,1293333 & Ocorre & Ocorre & Ocorre & Não & Ocorre & Ocorre & Ocorre & Ocorre & Ocorre & Ocorre \\
\hline Cenário 9 & 2,0920000 & Ocorre & Ocorre & Ocorre & Ocorre & Ocorre & Ocorre & Ocorre & Não & Ocorre & Ocorre \\
\hline Cenário10 & 1,8313333 & Ocorre & Ocorre & Não & Ocorre & Ocorre & Ocorre & Ocorre & Ocorre & Ocorre & Ocorre \\
\hline
\end{tabular}

Fonte: SOFTWARE PUMA, 2006. 


\section{O cenário mais provável}

A seguir, apresentam-se os eventos que possuem maior probabilidade de ocorrer, segundo os peritos entrevistados, e os possíveis desdobramentos que eles poderão trazer enquanto fatos objetivos para a apreciação das organizações do cluster calçadista.

\section{Acontecimentos favoráveis fora da competência da organização}

Os eventos apresentados a seguir referem-se àquilo que está fora das competências internas das empresas ou do cluster (oportunidades e ameaças), mas que pode interferir diretamente nos seus resultados.

- Evento 1 (Valorização do dólar): A ocorrência deste evento poderá levar ao aumento das exportações, aumento dos postos de trabalho na região e expansão do cluster do vale dos Sinos.

- Evento 4 (Concorrência com calçados de maior valor agregado): A ocorrência deste evento (cenário 10) possibilitará que os calçados produzidos no vale possam penetrar em mercados altamente competitivos, pois possuem qualidade e preço baixo, diferentemente do calçado europeu. Nesse sentido, existe um segmento de mercado onde esse calçado pode competir com grande vantagem, ou seja, o segmento intermediário.

- Evento 17 (Aumento no consumo de calçados no mercado interno): Historicamente, o consumo de calçados no mercado interno nas últimas décadas tem se mantido estável. Como 30\% da produção do vale dos Sinos é destinada para o mercado interno e $70 \%$ para o mercado externo, um aumento no consumo de calçados no mercado interno pode representar uma expansão quanto à participação no mercado brasileiro.

\section{Acontecimentos favoráveis dentro da competência da organização}

Os eventos apresentados a seguir referem-se àquilo que, internamente, as empresas ou o cluster podem modificar (pontos fracos) ou reforçar (pontos fortes) para melhorar a sua posição no mercado.

- Evento 2 (Utilização de marca própria): A ocorrência deste evento poderá gerar os seguintes fatos: o calçado produzido no vale passaria a ser comercializado com maior valor agregado e a utilização de marca própria facilitaria a comercialização, pois o calçado não seria exportado como uma commodity.

- Evento 6 (Expansão do mercado do vale para outros continentes): Como o vale dos Sinos é muito de- pendente de um único mercado externo, os Estados Unidos, que representam, em média, $60 \%$ a $70 \%$ das exportações dessa região, a expansão do mercado internacional do vale para outros continentes pode significar menos risco e novas oportunidades de negócios.

- Evento 12 (Condições das modalidades de transporte): A facilidade para o escoamento da produção é um importante fator na competitividade de uma determinada região, sendo que, atualmente, o vale dos Sinos é bem servido de acesso a diferentes modalidades de transporte.

- Evento 18 (Disponibilidade de operadores logísticos): A oferta de operadores logísticos especializados em gerenciar todas as atividades logísticas ou parte delas nas várias fases da cadeia de abastecimento, visando agregar valor aos produtos, é um evento extremamente importante a fim de que o vale dos Sinos possa oferecer produtos competitivos para diferentes mercados em todas as regiões do planeta. Nos últimos anos, a oferta desse serviço tem crescido significativamente. A região possui, pelo menos, quatro grandes operadores logísticos (Eichenberg, Kruger, Transcontinental e Mercúrio).

- Evento 19 (Disponibilidade de prestadores de serviços logísticos): No vale existem centenas de prestadores de serviços logísticos (empresas que apenas oferecem o transporte, e/ou a armazenagem, e/ou o processamento do pedido).

- Evento 20 (Condições de competitividade do cluster do vale dos Sinos): Atualmente, a região conta com todos os elementos da cadeia de suprimentos, entre eles, curtumes, fornecedores de máquinas e equipamentos, fornecedores de insumos etc., o que tem favorecido a competitividade do vale. Também merece especial atenção a utilização de tecnologias avançadas na produção, como CAD (Computer-Aided Design) e CAM (Computer-Aided Manufacturing), principalmente nas grandes empresas.

- Evento 21 (Instalação de uma agência de desenvolvimento regional): Com a ocorrência desse evento, a ADR poderia servir como um ponto de apoio para os empresários no contato com a agência central de desenvolvimento do governo federal, como uma orientação política comum, objetivando a sinergia entre os diferentes atores do vale. Para aproveitar esse evento favorável no futuro, devem-se unir as entidades representativas, como Assintecal (Associação Brasileira de Empresas de Componentes para Couro, Calçados e Artefatos), a Abicalçados (Associação Brasileira dos Fabricantes de Calçados), entre outras, facilitando o processo de inte- 
gração, pois já atuam, embora isoladamente, voltadas para o desenvolvimento da região.

\section{0 cenário de tendência}

Neste cenário, o único evento com alta probabilidade de ocorrência é o evento 6 (Expansão do mercado do vale dos Sinos para outros continentes). A não-ocorrência desse evento poderá fazer com que o vale dos Sinos permaneça dependente de um único mercado (EUA), correndo sérios riscos quanto à concorrência internacional, principalmente dos calçados asiáticos.

\section{0 cenário ideal}

No caso deste estudo, não foi selecionado nenhum evento desfavorável fora ou dentro da competência do objeto de estudo. Nesse sentido, o cenário ideal coincide com o cenário mais provável, ou seja, o cenário ideal só contempla eventos favoráveis.

\section{A INTEGRACÃO DOS CENÁRIOS PROSPECTIVOS COM A DINẦMICA DE SISTEMAS}

Para a integração entre os cenários gerados e a dinâmica de sistemas, foram selecionados os dez primeiros cenários, pois esses corresponderam a uma alta probabilidade (percentual calculado pelo software PUMA, por meio do teorema de Bayes) de ocorrência (63,70\%); os demais 1014 (um mil e quatorze), 36,30\%. Configurada a geração dos cenários, realizou-se a integração. Tal processo iniciou pelo destaque dos dez primeiros cenários, colocados numa planilha eletrônica Excel, onde foi indicada a ocorrência ou não dos eventos, um e zero, respectivamente.

$\mathrm{Na}$ montagem da planilha são descritos os cenários com seus respectivos dez eventos. Feito isso, calculou-se a média aritmética das notas dos sete peritos sobre o impacto que cada evento provocaria na produção. A média resultante foi multiplicada pela ocorrência ou não dos eventos. Assim, essas notas são o somatório da multiplicação das médias das notas dos peritos pela ocorrência ou não dos eventos.

Cabe salientar que as probabilidades dos dez cenários foram acumuladas, visando oportunizar a randomização (números aleatórios de 1 a 100 lançados pelo computador) na escolha dos cenários na Dinâmica de Sistemas. A acumulação dessas probabilidades possibilita uma maior ocorrência dos cenários 1, 2, 3 e 10, respectivamente, visto que são os cenários de maior probabilidade.

A simulação foi feita pelo software iThink. Para Zambon (1999), o surgimento de softwares mais portáteis, como o Stella/iThink, difundiu a Dinâmica de Sistemas, possibilitando que modelos concebidos a partir dessa metodologia pudessem ser simulados em locais menos providos de recursos computacionais. A abrangência da simulação contemplou um período de 60 meses (cinco anos). Nessa seleção, faz-se a ponderação de acordo com a sua probabilidade de ocorrência. Dessa forma, a escolha dos cenários na simulação é compatível com as probabilidades calculadas pelo software PUMA (Cenários Prospectivos).

O objetivo dessa integração é simular a produção de calçados no vale dos Sinos para os próximos cinco anos (do ano 2006 até 2010). As projeções partiram de 155 milhões de pares, a partir de dados fornecidos pela Abicalçados (Associação Brasileira das Indústrias de Calçados), tendo como base o ano 2005.

Na primeira simulação, a Tabela 4 mostra os resultados, considerando as notas dos peritos para os dez eventos definitivos. Essa tabela apresenta uma projeção crescente para a produção em milhões de pares, sendo o percentual de aumento entre os anos de 2006 e 2010 de 7,6\%. Esses resultados podem ser explicados porque a maior parte das notas dos peritos foi positiva aos eventos definitivos.

A Tabela 5 visa comparar as previsões feitas mediante as notas dos peritos (Dinâmica de Sistemas/software

Tabela 4 - Previsão da produção de calçados para o Vale dos Sinos nos próximos cinco anos, considerando as notas dos peritos

\begin{tabular}{|c|c|}
\hline ANO & EM MILHÕES DE PARES DE CALÇADOS \\
\hline 2006 & 158 \\
\hline 2007 & 161 \\
\hline 2008 & 164 \\
\hline 2009 & 167 \\
\hline 2010 & 170 \\
\hline Variação \% entre os anos de 2006 e 2010 & $7,6 \%$ \\
\hline
\end{tabular}

Fonte: SOFTWARE ITHINK/STELLA, 2006. 
iThink), com os cálculos realizados por meio da regressão polinomial quadrática, considerando os últimos dez anos de produção de calçados no vale dos Sinos. Isto é, para a validação dos resultados futuros, foi necessária uma regressão de dez anos passados. Identificou-se uma curva polinomial quadrática como a que melhor explicou o comportamento da produção nos últimos dez anos de produção de calçados no vale dos Sinos, visto que o coeficiente de regressão foi de 0,9246, significando que $92,46 \%$ dos dados foram explicados pela equação.

Na simulação feita com base na Dinâmica de Sistemas, observa-se um aumento linear da produção em milhões de pares de calçados para os próximos cinco anos. $\mathrm{Na}$ previsão realizada pela equação polinomial quadrática, ocorreu um crescimento mais acentuado.

\section{CONSIDERAÇÕES FINAIS}

Os resultados iniciais indicam uma tendência de recuperação no vale dos Sinos para os próximos cinco anos, visto que os cálculos feitos por meio da regressão polinomial quadrática validam as projeções realizadas pelo modelo proposto.

Cabe ainda destacar que a integração de Cenários Prospectivos à Dinâmica de Sistemas indicou a viabilidade da utilização conjunta dessas duas ferramentas, visto que se partiu de uma perspectiva estática (Cenários Prospectivos) para uma perspectiva dinâmica (Dinâmica de Sistemas). Essa combinação possibilitou a geração e interpretação dos cenários, bem como a sua simulação no tempo.

Por se tratar de um modelo sistêmico, cabe destacar que o processo de diagnóstico e prognóstico pode, a qualquer momento, ser reiniciado, de modo que os peritos poderiam, a cada rodada, aprender sobre a experiência vivida com o modelo em questão.

Além do objetivo de construir Cenários Prospectivos e integrá-los à Dinâmica de Sistemas, com vistas a diag- nosticar e prognosticar o setor calçadista, outra importante questão é indicar, aos diferentes atores dessa região, a possibilidade de decisões que possam proteger o vale dos Sinos contra ameaças, bem como aproveitar as oportunidades que poderão advir.

\section{REFERÊNCIAS}

ASSOCIAÇÃO BRASILEIRA DAS INDÚSTRIAS DE CALÇADOS. Resenha Estatística. Novo Hamburgo: Abicalçados, 2005.

ASSOCIAÇÃO BRASILEIRA DAS INDÚSTRIAS DE CALÇADOS Disponivel em http:// www.abicalcados.com.br. Acesso em 01.06.2005.

ASSOCIAÇÃO BRASILEIRA DE EMPRESAS DE COMPONENTES PARA COURO, CALÇADOS E ARTEFATOS. Disponível em http://www.assintecal.org.br. Acesso em 01.08.2005.

ANDERSON, P. Barreiras não tarifárias às exportações brasileiras no Mercosul: o caso de calçados. Rio de Janeiro: IPEA, 2001.

ANDRADE, A. L. Pensamento sistêmico: um roteiro básico para perceber as estruturas da realidade organizacional. REAd - Revista Eletrônica de Administração, 5. ed., v. 3, n. 1, jun. 1997. Disponível em http://read.adm. ufrgs.br/read05/artigo/andrade.htm. Acesso em 21.12.2004.

BASTOS, A. A. P. A dinâmica de sistemas e a compreensão de estruturas de negócio. 2003. 135 p. Dissertação de Mestrado em Administração, Faculdade de Administração, Economia e Contabilidade da Universidade de São Paulo, São Paulo, 2003.

BETHLEM, A. Estratégia empresarial: conceitos, processo e administração estratégica. 4. ed. São Paulo: Atlas, 2002.

COSTA, A. B. da. Competitividade da indústria de calçados: nota técnica setorial do complexo têxtil. In: COUTINHO, Luciano G. e outros (Coord) Estudo da Competitividade da Indústria Brasileira. Campinas: FECAMP. MCT; FINEP; PADCT, 1993 ,

FENSTERSEIFER, J. E. e outros. O complexo calçadista em perspectiva: tecnologia e competitividade. Porto Alegre: Ortiz, 1995.

Tabela 5 - Comparação entre as previsões feitas pelo software iThink e os cálculos de regressão polinomial quadrática

\begin{tabular}{|c|c|c|}
\hline ANO & PREVISÃO COM AS NOTAS DOS PERITOS & REGRESSÃO POLINOMIAL QUADRÁTICA \\
\hline 2006 & 158 & 159 \\
\hline 2007 & 161 & 163 \\
\hline 2008 & 164 & 167 \\
\hline 2009 & 167 & 172 \\
\hline
\end{tabular}


FERNANDES, A. C. Dinâmica de Sistemas e Business Dynamics: tratando a complexidade no ambiente de negócios. In: ENCONTRO NACIONAL DE ENGENHARIA DE PRODUÇÃO, $21^{\circ}, 2001$, Salvador. Anais XXI Salvador: ENEGP, 2001. Disponível em http://www.gpi.ufrj.br/pdfs/ artigos/Fernandes\%20-\%20Business\%20Dynamics\%20-\%20XXI\%20 ENEGEP\%20- \%202001.pdf. Acesso em 20.08.2004.

FRANCO, R. A. C. Processo de terceirização logística: uma abordagem de dinâmica de sistemas. 2005. 145 p. Dissertação de Mestrado em Engenharia de Transportes, Escola Politécnica da Universidade de São Paulo, São Paulo, 2005.

GODET, M. A "Caixa de ferramentas" da prospectiva estratégica. Cadernos do Centro de Estudos de Prospectiva e Estratégica. Lisboa: Cepes, 2000. Disponível em http://www.cnam.fr/lipsor/lips/conferences/data/bo-lipspo.pdf. Acesso em 15.01.2006.

GRUMBACH, R. J. Prospectiva: a chave para o planejamento estratégico. 2. ed. Rio de Janeiro: Catau, 2000.

HENKIN, H. Tendências Econômicas para a Indústria de Calçados e Componentes. Impacto Econômico Assintecal, Novo Hamburgo, n. 04, 2004.

HENKIN, H. Tendências Econômicas para a Indústria de Calçados e Componentes. Impacto Econômico Assintecal, Novo Hamburgo, n. 05, 2005.

MAANI, K. E.; CAVANA, R. Y. System thinking and modeling: understanding change and complexity. New Zealand: Pearson Education New Zealand, 2000
MARCIAL, E. C.; GRUMBACH, R. J. S. Cenários prospectivos: como construir um futuro melhor. 3. ed. Rio de Janeiro: FGV, 2005.

MARTELANC, R. Proposição e avaliação de política de hierarquização de fontes de financiamento sob restrições de capital. 1998. 294 p. Tese de Doutorado em Administração, Faculdade de Administração, Economia e contabilidade da Universidade de São Paulo, São Paulo, 1998

MORETTI, C. S. Cenários em segurança: visão prospectiva. São Paulo: Universidade Corporativa de Risco Empresarial (URE)/Brasiliano \& Associados, 2000. Disponível em http://www.brasiliano.com.br/ artigocen\%Elriosprospectivos.htm. Acesso em 10.01.2006.

PORTER, M. E. Competição: estratégias competitivas essenciais. Rio de Janeiro: Campus, 1999.

PUMA SOFTWARE. Versão 4.0. Disponível em http://www.brainstorming com.br. Acesso em 10.06.2005.

SOFTWARE ITHINK - STELLATM SYSTEMS THINKING FOR EDUCATION AND RESEARCH. Disponível em http://www.hps-inc.com. Acesso em 10.06.2005.

ZAMBON, A. C. Análise de fundo de pensão: uma abordagem de System Dynamics. 1999. 120 p. Dissertação de Mestrado em Produção, Faculdade de Engenharia da Universidade Federal de São Carlos, São Carlos, 1999 